\title{
PRÁTICAS PEDAGÓGICAS NA EDUCAÇÃO INCLUSIVA: REVISÃO SISTEMÁTICA
}

\author{
PEDAGOGICAL PRACTICES IN INCLUSIVE EDUCATION: \\ SYSTEMATIC REVIEW
}

\section{PRÁCTICAS PEDAGÓGICAS EN LA EDUCACIÓN INCLUSIVA: REVISIÓN SISTEMÁTICA}

\author{
LÊda Gonçalves de Freitas ${ }^{\mathrm{I}}$ \\ Carla Cristie de França Silva ${ }^{1}$ \\ Cláudia CRISTINA FuKUdA ${ }^{\mathrm{I}}$ \\ Gustavo Francisco Neto ${ }^{\mathrm{I}}$ \\ ${ }^{\text {I } U n i v e r s i d a d e ~ C a t o ́ l i c a ~ d e ~ B r a s i ́ l i a ~(U C B), ~ B r a s i ́ l i a / D F ~-~ B r a s i l ~}$
}

\begin{abstract}
RESUmo Neste artigo a inclusão escolar é analisada a partir das práticas pedagógicas, pressuposto essencial para a democratização da escola. As leis, as políticas públicas são fundamentais para o exercício da democracia social, mesmo no contexto de dificuldades de garantir os direitos sociais de educação, saúde, emprego, entre outros. O presente manuscrito teve como objetivo mapear estudos brasileiros publicados em periódicos nacionais nas áreas de Psicologia e Educação, que investigaram práticas pedagógicas no contexto da inclusão, e ainda refletir sobre as principais contribuições dessas pesquisas. Após busca sistemática na Biblioteca Virtual em Saúde - Psicologia (BVS-PSI) e no Scielo.br, período 2008-2018, com os descritores inclusão escolar, práticas pedagógicas, práticas inclusivas e aprendizagem, 18 artigos foram considerados. As contribuições dos artigos em relação às práticas pedagógicas inclusivas indicam a presença, ainda, de obstáculos para a garantia da inclusão escolar, sobretudo pelas dificuldades de infraestrutura e formação apropriada dos docentes para atuarem na área. Não obstante, observam-se práticas pedagógicas que visam superar uma educação bancária por meio de ações pedagógicas que provocam os estudantes a serem sujeitos ativos no seu processo de aprendizagem.
\end{abstract}

Palavras-chave: EducaÇão. Inclusão. Práticas pedagóGicas.

ABSTRACT In this article the school inclusion is analyzed from the pedagogical practices, essential presupposition for the democratization of the school. Laws, public policies are fundamental for the exercise of social democracy, even in the context of difficulties in guaranteeing the social rights of education, health, employment, among others. This manuscript 
aimed to map Brazilian studies published in national journals in the areas of Psychology and Education, which investigated pedagogical practices in the context of inclusion and also reflect on the main contributions of these studies. After systematically searching the Virtual Health Library - Psychology (VHL-PSI) and Scielo.br, period 2008-2018, with the descriptors school inclusion, pedagogical practices, inclusive practices and learning, eighteen articles were considered. The contributions of the articles in relation to inclusive pedagogical practices indicate the presence, still, of obstacles to the guarantee of the school inclusion, mainly due to the difficulties of infrastructure and proper formation of the teachers to work in the area. Nevertheless, there are pedagogical practices that aim to overcome a banking education through pedagogical actions that cause students to be active subjects in their learning process.

Keywords: Education. Inclusion. Pedagogical practices.

RESUMEN En este artículo se analiza la inclusión escolar a partir de prácticas pedagógicas, supuesto fundamental para la democratización de la escuela. Las leyes, las políticas públicas son fundamentales para el ejercicio de la socialdemocracia, incluso en el contexto de dificultades para garantizar los derechos sociales de educación, salud, empleo, entre otros. El presente manuscrito tuvo como objetivo mapear estudios brasileños publicados en revistas nacionales en las áreas de Psicología y Educación, que investigaban prácticas pedagógicas en el contexto de la inclusión, y reflexionar sobre los principales aportes de estas investigaciones. Luego de una búsqueda sistemática en la Biblioteca Virtual en Salud - Psicología (BVS-PSI) y Scielo.br, período 2008-2018, con los descriptores inclusión escolar, prácticas pedagógicas, prácticas inclusivas y aprendizajes, se consideraron 18 artículos. Los aportes de los artículos en relación a las prácticas pedagógicas inclusivas señalan la presencia, aún, de obstáculos para garantizar la inclusión escolar, especialmente por las dificultades de infraestructura y formación adecuada de los docentes para trabajar en la zona. Sin embargo, existen prácticas pedagógicas que apuntan a superar la educación bancaria a través de acciones pedagógicas que provocan que los estudiantes sean sujetos activos en su proceso de aprendizaje.

Palabras Clave: Educación. Inclusión. Prácticas pedagógicas.

\section{INTRODUÇÃo}

A Constituição Federal da República Brasileira assume a Declaração Universal dos Direitos Humanos (ONU, 1948) e, assim, garante educação e acesso à escola para todos os brasileiros sem nenhuma diferenciação, conforme prescreve o artigo 205: "A educação é direito de todos e dever do Estado e da família, será promovida e incentivada com a colaboração da sociedade, visando ao pleno desenvolvimento da pessoa, seu preparo para o exercício da cidadania e sua qualificação para o trabalho." (BRASIL, 1988).

Com efeito, a LDB n ${ }^{\circ} 9.394$ (1996), no artigo 58, institui a Educação Especial como uma modalidade de educação escolar, devendo ser ofertada, preferencialmente, na rede regular de ensino. A mesma Lei, em seu artigo 59, inciso I, assinala que os sistemas de en- 
sino devem assegurar às pessoas com deficiência "currículos, métodos, técnicas, recursos educativos e organização específicos, para atender às suas necessidades." (BRASIL, 1996).

O marco legal da Educação Especial no Brasil se referencia nos documentos internacionais sobre a temática, tais como: Declaração de Salamanca (UNESCO, 1994) e Convenção Internacional sobre os Direitos das Pessoas com Deficiência (ONU, 2006). Todo esse marco regulatório contribuiu para o país apresentar a Política Nacional de Educação Especial na Perspectiva da Educação Inclusiva, que tem como objetivo garantir o acesso, a participação e a aprendizagem dos estudantes com deficiência, transtornos globais do desenvolvimento e altas habilidades/superdotação nas escolas regulares (BRASIL, 2008).

É importante ressaltar que as diretrizes internacionais são orientações para os países e no caso da Convenção Internacional predita, o Brasil assumiu através da aprovação no Congresso Nacional do Decreto Legislativo ${ }^{\circ} 186$, de 9 de julho de 2008. Foi promulgada pelo Presidente da República, por meio do Decreto $\mathrm{n}^{\circ}$ 6.949, de 25 de agosto de 2009. A Declaração de Salamanca, sendo o Brasil signatário, foi essencial para difundir o debate em torno da regulamentação e implementação de políticas públicas direcionadas às pessoas com deficiência.

A Lei Brasileira de Inclusão da Pessoa com Deficiência - Estatuto da Pessoa com Deficiência (BRASIL, 2015), em seu artigo 27, assegura "[...] sistema educacional inclusivo em todos os níveis e aprendizado ao longo de toda vida". Com isto, o objetivo de sistemas educacionais inclusivos é o de possibilitar desenvolvimento abrangente à pessoa com deficiência no que diz respeito às habilidades físicas, sensoriais, intelectuais e sociais. Isto posto, o artigo 28 , inciso II, especifica que os sistemas educacionais devem garantir as condições de acesso, permanência, participação e aprendizagem a todo o público-alvo, ou seja, os estudantes com deficiência, transtornos globais do desenvolvimento e altas habilidades/superdotação.

Por conseguinte, a educação especial, na perspectiva da educação inclusiva (BRASIL, 2008) constitui-se como proposta pedagógica da escola. Isto implica, de acordo com o artigo $1^{\circ}$ do Estatuto da Pessoa Deficiência, que os sistemas educacionais devem assegurar e promover o exercício dos direitos e das liberdades fundamentais de todas as pessoas com deficiência tendo em vista o desenvolvimento de sua cidadania (BRASIL, 2015). Portanto, um ambiente escolar inclusivo exige participação do estudante com deficiência e aprendizagem com possibilidade de continuidade dos estudos, atendimento educacional especializado, acessibilidade arquitetônica e materiais pedagógicos diversificados.

O Plano Nacional de Educação (PNE), Lei n 13.005/2014 (BRASIL, 2014), em sua Meta 4, indica a universalização do acesso à educação básica para a população de 4 a 17 anos com deficiência, transtornos globais do desenvolvimento e altas habilidades ou superdotação, além do atendimento educacional especializado.

Com a meta proposta no PNE, os sistemas educacionais brasileiros têm prazo até 2020 para realizar as modificações nas suas estruturas físicas, bem como repensar o ensino para que os direitos de crianças e adolescentes com deficiência sejam efetivamente garantidos quanto ao seu desenvolvimento integral, priorizando a aprendizagem de todos.

A prática pedagógica no contexto da inclusão pode ser compreendida como as ações dos agentes educacionais, gestores da educação, professores, orientadores educacionais, psicólogos, entre outros, com vistas a garantir o processo de ensino-aprendizagem. No entanto, a prática pedagógica docente é o núcleo central do processo de ensino e aprendi- 
zagem, no cotidiano da sala de aula, promovendo a mediação, a interação entre professores e estudantes a partir do conhecimento, envolvendo um fazer com múltiplas dimensões: relacional, intencional e sistematizada (GUEDES; LEITÃO, 2016).

A dimensão relacional abrange a perspectiva freireana da prática pedagógica para a humanização, cuja essência é o diálogo. Para isto, os educandos são convocados ao conhecimento, à reflexão profunda, possibilitando a compreensão do contexto social permeado pelos saberes historicamente construídos. Logo, a ação docente, e sua intencionalidade reportam para um projeto de prática de sala de aula que provoque o estudante a pensar, a saber ser e estar no mundo. A prática pedagógica requer sistematização, a qual busca construir situações de ensino desafiadoras, problematizadoras, com interações e articulações entre os conteúdos e o contexto social, mas planejadas, estruturadas (FREIRE, 2003).

Deste modo, o presente manuscrito teve como objetivo realizar uma revisão sistemática de artigos científicos sobre práticas pedagógicas na inclusão escolar. Além disso, salientar as principais contribuições dessas pesquisas para a consolidação da educação inclusiva, visto que, não somente o acesso à educação, mas a permanência com aprendizagem e desenvolvimento é imprescindível para garantir o sistema educacional inclusivo.

\section{Método}

Esta pesquisa apresenta como método a revisão sistemática. De acordo com Costa e Zoltowski (2014), este método potencializa a busca por resultados de forma organizada e consiste num trabalho de reflexão crítica sobre uma determinada temática. Assim, para a presente revisão foram utilizadas as etapas apresentadas pelos autores, quais sejam: 1) delimitação do tema de pesquisa; 2) definição das fontes de dados; 3) definição das palavras-chave; 4) busca e armazenamento dos resultados; 5) seleção dos artigos; 6) retirada das informações dos artigos selecionados; 7) avaliação, síntese e interpretação dos dados dos artigos.

Com o objetivo de identificar a produção científica sobre as práticas pedagógicas na inclusão escolar, a revisão sistemática se realizou por meio de um levantamento de pesquisas brasileiras indexadas na base SciELO Brasil da Biblioteca Virtual em Saúde - Psicologia (BVS-PSI). O intervalo de tempo definido foi de 2008 a 2018. Os descritores considerados abrangeram a dimensão da inclusão, destacando as práticas pedagógicas.

A busca iniciou com os descritores "inclusão escolar e práticas pedagógicas" que resultou em 18 produções científicas. Ao utilizar o operador booleano OU, foram identificadas mais sete publicações. Ao considerar que os resultados foram baixos, optou-se por ampliar os descritores e nova busca foi feita com "práticas inclusivas e aprendizagem", o resultado foi de seis artigos científicos. Quando se utilizou o operador booleano OU, obteve-se mais três produções.

No total, foram encontrados 34 artigos. Como critérios de exclusão foram definidos duplicidade, pesquisas fora do período de 2008 a 2018, estudos realizados fora do Brasil e artigos que não tratavam de práticas pedagógicas no contexto da inclusão. A leitura dos resumos e conclusões resultou na seleção de 18 artigos.

A retirada das informações dos artigos selecionados para avaliação e síntese dos dados considerou as revistas em que os trabalhos foram publicados, a autoria, que traz o percen- 
tual de homens e mulheres participantes, os principais temas desenvolvidos, a fundamentação teórica e o método.

Após a análise, os resultados foram interpretados e organizados em quatro categorias, a saber: 1) Dificuldades gerais para realização do trabalho pedagógico; 2) Concepções de professores sobre a prática pedagógica na inclusão escolar; 3) Prática de gestores e psicólogos na inclusão escolar; 4) Práticas pedagógicas na sala de aula.

As categorias foram estabelecidas a posteriori, isto é, resultantes da leitura e interpretação dos artigos analisados. Outrossim, as categorias abrangem as características do conhecimento em torno das práticas pedagógicas identificadas nos estudos analisados.

\section{Resultados}

Foi analisado um total de 18 artigos, a metade deles publicados nos anos de 2014 e 2015 e, principalmente, em periódicos de educação ou educação especial (13) com menor participação em periódicos de psicologia. Os pesquisadores autores dos artigos provinham da Região Sudeste (11), predominantemente (Tabela1).

Tabela 1 - Número de documentos por ano de publicação, área de conhecimento do periódico e região dos pesquisadores $(\mathrm{N}=18)$

\begin{tabular}{c|c|l|c|l|c}
\hline $\begin{array}{c}\text { Ano de } \\
\text { Publicação }\end{array}$ & N (\%) & $\begin{array}{c}\text { Região dos } \\
\text { Pesquisadores }\end{array}$ & N (\%) & $\begin{array}{c}\text { Área do } \\
\text { periódico }\end{array}$ & N (\%) \\
\hline 2008 & $2(11,1)$ & Sudeste & $11(61,1)$ & Educação & $7(38,9)$ \\
2009 & $1(5,5)$ & Sul & $3(16,7)$ & Educação especial & $6(33,3)$ \\
2012 & $2(11,1)$ & Centro-Oeste & $2(11,1)$ & Psicologia & $5(27,8)$ \\
2013 & $1(5,5)$ & Nordeste & $1(5,5)$ & & \\
2014 & $4(22,2)$ & Norte & $1(5,5)$ & & \\
2015 & $5(27,8)$ & & & & \\
2016 & $2(11,1)$ & & & & \\
\hline 2018 & $1(5,5)$ & & & & \\
\hline
\end{tabular}

Fonte: Elaborada pelos autores.

A metade dos pesquisadores primeiros autores dos artigos provinha de universidades públicas federais (9). Dentre as universidades pública estaduais destaca-se a participação de pesquisadores da Universidade de São Paulo (2) e Universidade Estadual Paulista (2). Há uma menor participação de pesquisadores provenientes de instituições de ensino superior (IES) privadas (3) e apenas em um artigo o autor principal estava associado a uma universidade estrangeira (italiana) (Tabela 2). 
Tabela 2 - Tipo e nome das instituições de vínculo dos primeiros autores dos artigos analisados $(\mathrm{N}=18)$

\begin{tabular}{lc}
\hline Tipo de IES/nome da IES & Autor (ano) \\
\hline Universidade Federal de Minas Gerais & Gomes e Mortimer (2008) \\
Universidade Federal do Pará & Anjos, Melo, Silva, Rabelo e Araújo (2013) \\
Universidade de Brasília & Silva, Silva e Silva (2014) \\
Universidade Federal Rural do Rio & Pletsch (2014a, 2014b) \\
de Janeiro & \\
Universidade Federal de São Carlos & Benitez e Domeniconi (2015, 2018) \\
Universidade Federal de Santa Maria & Franco e Guerra (2015) \\
Universidade Federal do Rio & Santos e Martins (2015) \\
Grande do Norte & \\
\hline \multicolumn{2}{c}{ Pública Estadual (N = 5) } \\
\hline Universidade Estadual de Maringá & Leonardo (2008) \\
Universidade de São Paulo & Silva e Leme (2009); Briant; Oliver (2012) \\
Universidade Estadual Paulista & Caramori e Dall’Acqua (2015); \\
& Louzada e Martins (2016) \\
\hline & Privada (N = 3) \\
\hline Universidade Católica de Campinas & Gomes e Souza (2012) \\
Universidade do Vale do Rio dos Sinos & Scherer e Dal’Igna (2015) \\
Universidade Católica de Brasília & Santana, Purificação, Teperino, \\
& Taceli e Pessoa (2016) \\
\hline Universidade de Macerata & Giaconi e Rodrigues (2014) \\
\hline
\end{tabular}

Fonte: Elaborada pelos autores.

Em relação às temáticas dos artigos no contexto das práticas pedagógicas na inclusão escolar, observam-se estudos que enfatizam as dificuldades da rede escolar para desenvolver o trabalho pedagógico, como falta de infraestrutura e recursos pedagógicos, formação adequada dos professores, além da falta de suporte especializado para apoiar a inclusão escolar (LEONARDO, 2008; GOMES; SOUZA, 2012; PLETSCH, 2014a, 2014b). Outra temática apresentada diz respeito à visão dos professores sobre o trabalho pedagógico na inclusão escolar (ANJOS et al., 2013; LOUZADA; MARTINS, 2016). Ainda há estudos de práticas pedagógicas que favorecem a aprendizagem (BENITEZ; DOMENICONI, 2015). Observou-se a prática dos agentes como diretor de escola e psicólogo na inclusão escolar (SILVA; LEME, 2009; BENITEZ; DOMENICONI, 2018).

Quanto às práticas pedagógicas em sala de aula, verificou-se o fazer pedagógico tradicional (BRIANT; OLIVER, 2012; SANTOS; MARTINS, 2015), assim como práticas que utilizam a mediação pedagógica, o diálogo e o brincar para potencializar a aprendizagem no contexto da inclusão escolar (GOMES; MORTIMER, 2008; CARAMORI; DALL'ACQUA, 2015; SANTANA et al., 2016; SILVA; SILVA; SILVA, 2014; GIACONI; RODRI- 
GUES, 2014). Além dessas práticas, observou-se estudo sobre a prática de professores junto ao atendimento educacional especializado (SCHERER; DAL'IGNA, 2015).

A fundamentação teórica dos estudos foi diversificada, tendo sido utilizado: abordagem histórico-cultural de Vigotski (PLETSCH, 2014a; SILVA; LEME, 2009); a teoria da subjetividade de González Rey (GOMES; SOUZA, 2012); a teoria da modificabilidade cognitiva estrutural (CARAMORI; DALL'ACQUA, 2015); a perspectiva pós-estruturalista (SCHERER; DAL'IGNA, 2015). Os demais estudos refletem sobre o processo de inclusão no Brasil, destacando as dificuldades e desafios sem especificar teoria.

Dos 18 artigos selecionados, 15 se classificam como relatos de pesquisa $(83,33 \%)$, enquanto três se apresentam como pesquisas de revisão bibliográfica e revisão sistemática $(16,66 \%)$. Todos os artigos empíricos utilizaram o método qualitativo com variadas técnicas de coleta de dados, de forma combinada. A técnica mais utilizada foi a entrevista semiestruturada (PLETSCH, 2014a, 2014b; ANJOS et al., 2013; LOUZADA; MARTINS, 2016; SILVA; LEME, 2009; SANTOS; MARTINS, 2015; CARAMORI; DALL'ACQUA, 2015; FRANCO; GUERRA, 2015; BRIANT; OLIVER, 2012; SCHERER; DAL'IGNA, 2015; GOMES; SOUZA, 2012; SILVA; LEME, 2009). Foram também utilizadas técnicas de observação como: observação participante (SANTOS; MARTINS, 2015; CARAMORI; DALL'ACQUA, 2015), filmagens de práticas pedagógicas (PLETSCH, 2014a, 2014b), além de análise documental (BENITEZ; DOMENICONI, 2015; SILVA; LEME, 2009), questionário com questões abertas (LEONARDO, 2008) e intervenção com grupos (BENITEZ; DOMENICONI, 2018) (Gráfico 1).

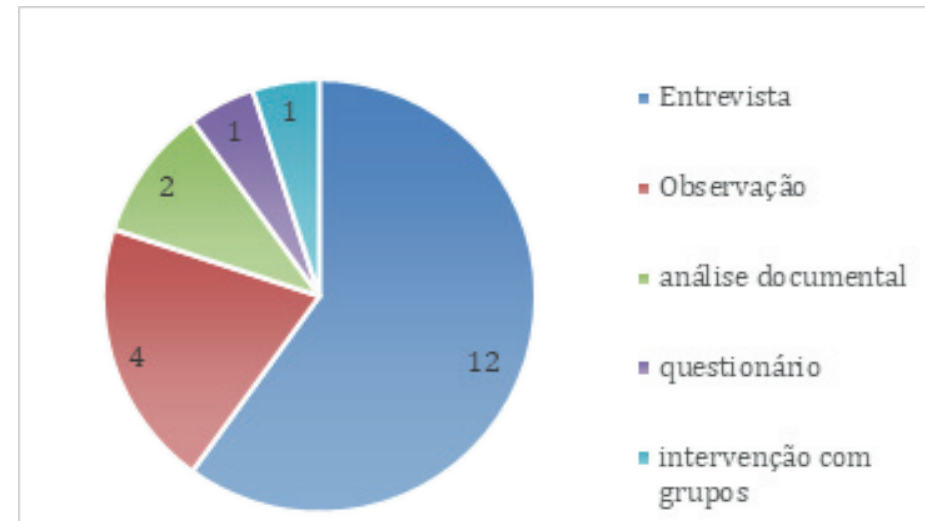

Gráfico 1 - Número de técnicas de coletas de dados utilizadas pelos artigos empíricos Fonte: Elaborada pelos autores.

A maioria (11) dos artigos que relataram pesquisas empíricas tiveram como participantes professores (PLETSCH, 2014a, 2014b; LOUZADA; MARTINS, 2016; ANJOS et al., 2013; LEONARDO, 2008; GOMES; SOUZA, 2012; SANTOS; MARTINS, 2015; FRANCO; GUERRA, 2015; BRIANT; OLIVER, 2012; SCHERER; DAL'IGNA, 2015; BENITEZ; DOMENICONI, 2018). Nos artigos também tiveram como participantes estudantes (CARAMORI; DALL'ACQUA, 2015; SILVA; LEME, 2009; GOMES; MORTIMER, 2008; BENITEZ; DOMENICONI, 2018); gestores (PLETSCH, 2014a, 2014b; ANJOS et al., 2013; SILVA; LEME, 2009); psicólogo escolar (BENITEZ; DOMENICONI, 
2018); coordenador pedagógico (BRIANT; OLIVER, 2012) e, no artigo de Briant e Oliver (2012) também houve a participação de um agente externo à escola, especificamente, um representante do Centro de Formação e Acompanhamento à Inclusão (Gráfico 2).

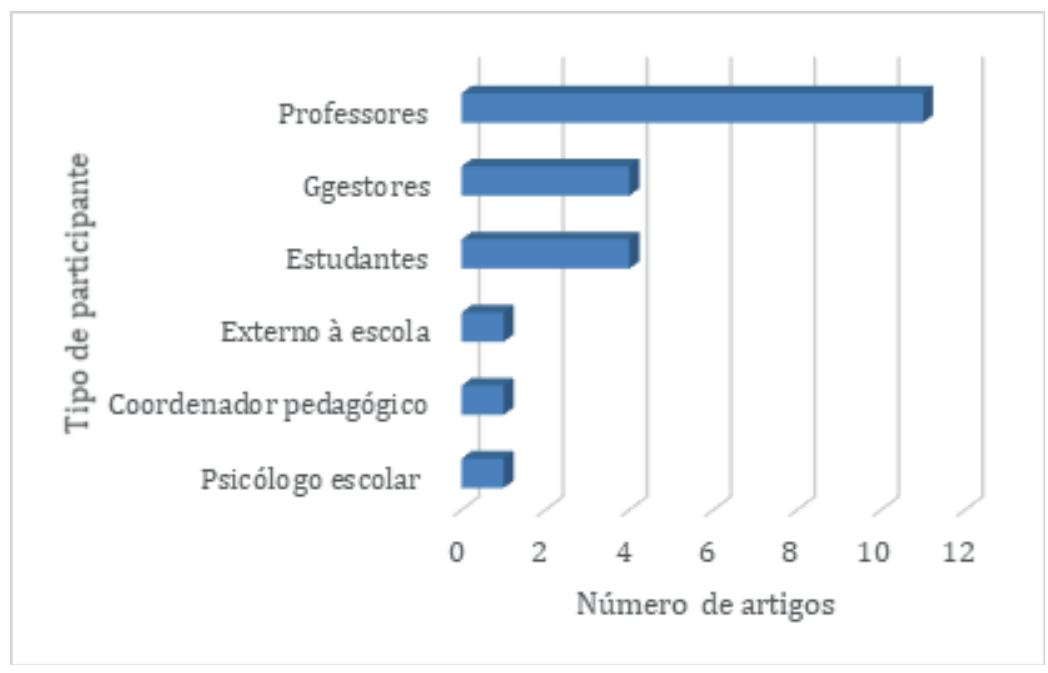

\section{Gráfico 2 - Participantes dos artigos empíricos}

Fonte: Elaborada pelos autores.

\section{Discussão}

O presente estudo teve como objetivo mapear estudos brasileiros publicados em periódicos nacionais nas áreas de Psicologia e Educação, que investigaram práticas pedagógicas inclusivas. Buscou-se também refletir sobre as principais contribuições dessas pesquisas para a construção de práticas pedagógicas exitosas na educação inclusiva.

Os resultados organizados em quatro categorias oportunizaram destacar as principais contribuições das produções analisadas para a construção de práticas pedagógicas exitosas no âmbito da inclusão escolar.

\section{Dificuldades gerais para realização do trabalho pedagógico}

Os resultados para esta categoria salientam obstáculos enfrentados pela rede escolar quanto à infraestrutura, recursos pedagógicos e formação adequada dos professores para realizar o trabalho pedagógico na inclusão escolar (LEONARDO, 2008; PLETS$\mathrm{CH}, 2014 \mathrm{a}, 2014 \mathrm{~b})$. Observam-se contradições quanto ao processo de implantação da educação inclusiva. Por um lado, há dados que afirmam que a inclusão escolar tem tido êxito sobretudo na infraestrutura física, ao mesmo tempo, há resultados que destacam as dificuldades da inclusão escolar quanto às questões de infraestrutura física (LEONARDO, 2008). Isso sugere que há um esforço dos sistemas de educação em ofertar a infraestrutura física para a implementação da inclusão, por um lado, porém, por outro lado, não dão conta das amplas necessidades de realização da acessibilidade física que envolve adequação arquitetônica. Esta acessibilidade requer a remoção de barreiras para que todos os estudantes tenham amplo acesso ao espaço escolar. 
Os resultados analisados nesta categoria apontaram as insuficiências da formação dos professores para o desenvolvimento do trabalho pedagógico bem como a falta dos recursos para o atendimento pedagógico. Constata-se que há avanço na legislação educacional quanto à inclusão escolar, mas há inúmeros problemas a serem enfrentados, como a falta de suportes diversificados e extensivos para as diferentes deficiências presentes no contexto escolar, e a precariedade das condições de trabalho dos professores, fatores que repercutem negativamente na educação inclusiva (LEONARDO, 2008; PLETSCH, 2014a, 2014b).

A formação de professores para a educação inclusiva requer programas de formação continuada que comportem processos de capacitação docente que consigam, efetivamente, atuar nas necessidades reais de sala de aula. Para tanto, currículos flexíveis para a escolarização, e percepção de todos os agentes educacionais, em particular, os professores, da importância de garantir o direito de aprendizagem dos estudantes com deficiência. Torna-se necessário, portanto, conceber que o aprender das crianças com deficiência é, sobretudo, assegurar o direito à educação (PLETSCH, 2014b).

Ainda sobre a formação de professores para educação inclusiva, Gomes e Souza (2012) acentuam problemas na formação inicial e continuada. Em relação à formação inicial, os autores compreendem que a falta de reflexão crítica e o uso de metodologias descontextualizadas são fatores que impossibilitam os docentes de terem percepções políticas, econômicas, sociais e ideológicas sobre a educação no país e, principalmente, compreender as questões referentes às políticas de inclusão. Com tal formação, os professores não produzem novos sentidos para a inclusão, a partir da formação continuada. Esta formação poderia ser assumida como tarefa primeira das instituições escolares, com vistas a refletir sobre a inclusão e produzir práticas pedagógicas que, efetivamente, contribuam com a aprendizagem e o desenvolvimento dos estudantes da educação especial.

\section{Concepções de professores sobre a prática pedagógica na inclusão escolar}

Os resultados referentes às concepções de professores sobre a prática pedagógica na inclusão escolar, indicam a presença de oscilações quanto à compreensão de que a inclusão deve envolver um processo com participação de vários agentes, e, ainda, uma visão idealizada, juntamente com desconhecimento das especificidades do aprender das crianças com deficiência e os seus potenciais (ANJOS et al., 2013).

Para Anjos et al. (2013) e Louzada e Martins (2016), há a necessidade do professor superar a visão limitadora da deficiência do estudante especial. Percebe-se que essa visão é redutora e coloca os estudantes em categoria inferior. Portanto, há que insistir nas práticas de ensino que acolham as demandas educacionais dos estudantes com deficiências, sem utilizar a dimensão "deficiência", para impossibilitar o desenvolvimento desses estudantes. A prática inclusiva institucional exige aprofundados conhecimentos acadêmicos que reconhecem os ritmos e processos diversos como flexibilizar o ensino e currículo escolar.

A formação dos professores para a inclusão aparece nos vários estudos analisados. Benitez e Domeniconi (2015) ressaltam a necessidade de capacitação teórica dos docentes para lidar com as práticas inclusivas. Na mesma direção, Santos e Martins (2015) asseveram o papel dos investimentos públicos na formação de professores numa perspectiva inclusiva, para que as adequações curriculares em sala de aula sejam compatíveis com as 
urgências dos estudantes. Gomes e Souza (2012) evidenciam que os espaços escolares devem investir em condições nas quais os professores possam se posicionar, pensar, refletir criticamente acerca da inclusão, pois discordar, concordar e criticar são essenciais para desenvolver a educação inclusiva.

\section{Prática de gestores e psicólogos na inclusão escolar}

Este estudo, ao tratar de práticas pedagógicas na inclusão, considerou importante avocar pesquisas com agentes da educação, não somente os professores. Deste modo, destacam-se as pesquisas de Silva e Leme (2009) e de Benitez e Domeniconi (2015), que estudaram o desempenho do diretor de escola e do psicólogo na inclusão escolar, respectivamente.

Nesta categoria sobressai o estudo de Silva e Leme (2009) sobre o papel do diretor na constituição de uma cultura escolar inclusiva, a partir do referencial teórico da psicologia histórico-cultural. Os autores destacam a importância da reflexão sobre os diversificados aspectos que constituem a cultura escolar, como as pessoas, os administrativos e os pedagógicos. Assim, consideram que, quanto mais a gestão escolar for democrática, mais a cultura educacional inclusiva estará presente para melhor trabalhar a aprendizagem e o desenvolvimento do estudante com deficiência. Com efeito, a democratização da gestão e a educação inclusiva estão diretamente inter-relacionadas. Para os autores, não são as características individuais que vão garantir uma escola democrática, mas a produção de contextos escolares democráticos que, necessariamente, envolvem a implantação de políticas públicas. $\mathrm{O}$ diretor, num contexto favorável às práticas democráticas, tem influência direta na construção de uma cultura inclusiva. Com isto, há interferência objetiva em todo o contexto escolar para que a inclusão efetivamente seja alcançada.

O estudo de Benitez e Domeniconi (2018), realizado com psicólogos no processo de inclusão escolar, baseou-se em intervenções dirigidas aos professores e pais de estudantes com autismo e deficiência intelectual, com vistas ao ensino da leitura e escrita. A pesquisa destaca a atuação do psicólogo diretamente no processo de aprendizagem dos estudantes com deficiência.

Observa-se que o psicólogo, ao produzir condições de monitoramento de intervenções com os professores e pais para que alcancem os estudantes e as aprendizagens, por meio de práticas que consideram os fatores sociais e culturais, constitui-se como o profissional que pode e deve atuar para a inclusão de estudantes com deficiência. Deste modo, é possível superar a prática diagnóstica, tão presente no contexto do psicólogo escolar, e, assim, contribuir no processo de mediação de aprendizagem, com vistas ao desenvolvimento de todos os estudantes.

Dessa forma, diretores, psicólogos, todos os agentes do contexto escolar devem operar, conjuntamente, com pais e professores para uma prática exitosa da inclusão escolar que, necessariamente, envolve ações pedagógicas para a aprendizagem e desenvolvimento de todos os estudantes.

\section{Práticas pedagógicas na sala de aula}

Neste estudo, verificou-se a diversificação de práticas pedagógicas no contexto da inclusão escolar. Os estudos de Briant e Oliver (2012) e de Santos e Martins (2015) revelam 
que há, ainda, uma presença acentuada de um fazer pedagógico tradicional no cotidiano das salas de aula. Estratégias de ensino como aulas expositivas e pouco protagonismo do estudante, o uso de uma pedagogia mais de transmissão com poucas adequações curriculares, além da indisponibilidade de materiais pedagógicos, limitam uma ação pedagógica significativa para a aprendizagem de todos os estudantes.

O estudo de Santana et al. (2016) abrangeu o ato de brincar como um dos recursos da inclusão escolar. Para os autores que estudaram o brincar no contexto de crianças com transtornos do espectro autista (TEA), a ação do brincar pode estimular a imaginação, a interação entre os pares, a memória, a atenção, o pensar, a linguagem e internalização de regras e normas sociais. Com efeito, o brincar não pode ser entendido apenas como diversão, mas como estratégia de ensino e aprendizagem. Portanto, o brincar enquanto ação pedagógica na inclusão escolar situa-se numa pedagogia em que os estudantes são ativos, participativos, protagonistas, desenvolvendo-se com os pares e na ludicidade.

Gomes e Mortimer (2008), num estudo com estudantes de química, buscaram construir histórias singulares por meio de trajetórias escolares, pertencimentos éticos, classe social e gênero. Assim, os autores evidenciaram que os processos de inclusão/exclusão são construídos no cotidiano da sala de aula, e garantir a inclusão é assegurar o aprendizado na escola. Para tanto, a construção de oportunidades de ensino e aprendizagem com metodologias diversificadas, as quais envolvam participação dos estudantes e interações em sala de aula, bem como o diálogo e trabalhos em pequenos grupos, são práticas fundamentais para garantir a inclusão. De todo modo, de acordo com os autores, este processo só é possível quando o professor compreende que o seu papel é de mediação da aprendizagem. Assim, incluir diz respeito à uma prática pedagógica mais dialógica e que promova mais protagonismo estudantil.

A educação de pessoas com deficiência intelectual severa, por meio do estudo de estratégias pedagógicas utilizadas por professores, é abordado por Caramori e Dall'Acqua (2015). Os autores evidenciaram traços de práticas pedagógicas relacionadas ao conceito de aprendizagem mediada, conforme a teoria da Experiência de Aprendizagem Mediada. Apesar de os professores não conhecerem a perspectiva da teoria da aprendizagem mediada, observou-se que a mediação é aplicada nas ações de ensinar. Diante disso, os autores asseveram que uma atuação pedagógica na concepção de mediação oferece mais e melhores oportunidades de aprendizagem dos estudantes no contexto inclusivo.

Silva et al. (2014) realizaram estudo com estudantes surdos sobre as estratégias pedagógicas utilizadas ao longo processo de escolarização bem como quais docentes marcaram suas trajetórias escolares. Os estudantes surdos mostraram que ainda há pouca interação entre os próprios estudantes surdos, além da não proficiência dos professores em Libras. Com isto, o desempenho acadêmico é prejudicado, tendo em vista a imprescindibilidade do uso da Libras para aprendizagem e desenvolvimento do estudante surdo.

Destarte, para a aprendizagem do estudante surdo, a importância da Libras, e a utilização de recursos imagéticos são considerados estratégias pedagógicas essenciais para que esse estudante tenha êxito em sua trajetória acadêmica. À vista disso, os autores afirmam a necessidade de implantação de projetos bilíngues com vistas ao alcance de maior comprometimento do estudante surdo com seu processo de aprendizagem. 
O artigo de Giaconi e Rodrigues (2014) apresenta uma reflexão sobre as especificidades da síndrome do autismo e possibilidades de ação para o processo de inclusão escolar. Assim, os autores apresentam indicações de estruturação de uma escola que busca atender o estudante autista. Para tanto, compreendem como necessário colocar os sujeitos autistas para se situarem com facilidade no espaço e num tempo previsível. Deste modo, terão consciência de onde estão, com quem, o que pode acontecer, e o que podem fazer.

Um ambiente escolar que possibilite o sujeito autista se movimentar exige pontos de referência visíveis e concretos desde quando o estudante acessa a escola. Além disso, a organização da sala de aula deve utilizar espaços e mobiliários estáveis e fixos para o desenvolver as atividades acadêmicas. Os materiais devem ser de acesso fácil, com imagens e cores que facilitem o acesso e a compreensão. Portanto, simples indicações de organização do espaço bem como do tempo favorecem o sujeito situar-se no ambiente escolar e, assim, conseguir realizar as atividades e ter aprendizagens mais significativas, conforme os autores supracitados.

Scherer e Dal'Igna (2015) apresentam parte de resultados de um estudo que investigou os discursos que constituem as práticas pedagógicas de professoras no Atendimento Educacional Especializado (AEE). Os resultados revelaram que as práticas de professores no AEE são marcadas por discursos legais, médicos, psicológicos, psicopedagógicos e pedagógicos. Ademais, os autores mostram que as professoras do AEE pensam, agem, em alguns aspectos como psicólogas, faltando uma ênfase maior na intervenção pedagógica.

Os autores chamam a atenção para a necessidade de refletir sobre o papel do AEE no processo de inclusão escolar, considerando que as práticas desenvolvidas neste atendimento estão voltadas, com maior destaque, para o atendimento clínico-terapêutico, em que os discursos presentes dos profissionais estudados são atravessados pelo legalismo, visão médica, psicológica, psicopedagógica e pedagógica, os quais contribuem para um sistema de normalização que regula o que será feito como sendo uma boa prática. As autoras destacam que o foco é na correção e na normalização dos estudantes que são encaminhados para o AEE.

\section{CONSIDERAÇões FINAIS}

A revisão sistemática, apresentada, permitiu agrupar e analisar estudos relevantes que descrevem práticas pedagógicas no contexto da inclusão escolar. Portanto, o olhar para a inclusão a partir das ações de ensino-aprendizagem possibilitou visualizar o processo de inclusão escolar, para além das suas dificuldades e do acesso dos estudantes.

A prática pedagógica na inclusão escolar evidenciou as ações dos diversos agentes educacionais para garantir a aprendizagem dos educandos com deficiência, e, também, o processo de ensinar e aprender em sala de aula.

O estudo evidenciou a presença, ainda, de obstáculos no que se refere ao acesso à infraestrutura adequada, aos recursos pedagógicos, bem como a formação compatível dos docentes para atuarem na inclusão escolar. No entanto, há estudos, em menor quantidade, que evidenciam a existência de estrutura física apropriada para implementação da inclusão.

A formação dos docentes para a inclusão escolar é abordada em várias pesquisas, as quais indicam a necessidade de capacitação teórica para superar a visão limitadora da defi- 
ciência. Os estudos analisados sugerem que a formação docente precisa insistir no reconhecimento dos ritmos diversos dos estudantes, flexibilizar currículos e possibilitar práticas pedagógicas com adequações curriculares compatíveis com as potencialidades dos estudantes.

O papel dos agentes educacionais, como diretores e psicólogos é apresentado como essencial para viabilizar uma cultura escolar inclusiva. Deste modo, a gestão escolar pode impulsionar as práticas democráticas no cotidiano, as quais fortalecem a cultura no dia a dia da escola e favorecem, ainda mais, a aprendizagem e o desenvolvimento dos estudantes com deficiência. Do mesmo modo, o psicólogo escolar que atuar para além do diagnóstico, fundamentando-se em intervenções com pais e professores com vistas à consideração de fatores sociais e culturais dos estudantes, terá, portanto, melhores condições de alcançar a aprendizagem dos estudantes com deficiências e favorecer o seu desenvolvimento.

Sobre as práticas pedagógicas efetivamente desenvolvidas na sala de aula, a revisão elaborada indicou uma variedade de práticas e uma presença marcante da pedagogia tradicional. Aulas expositivas com pouca ou quase nenhuma ação discente; insuficientes adequações curriculares e materiais pedagógicos exíguos persistem no cotidiano escolar.

Destaca-se, a presença de práticas pedagógicas de professoras no Atendimento Educacional Especializado (AEE), que revela a ação docente voltada ao atendimento psicológico, ao invés de atender às funções do AEE que prevê a identificação, elaboração e organização de recursos pedagógicos e de acessibilidade com vistas a eliminar as barreiras para a plena aprendizagem dos estudantes com deficiência.

Por outro lado, há práticas pedagógicas em que o estudante é protagonista do seu processo de aprendizagem, a partir do ato de brincar como forma de estimular a imaginação, a interatividade, a memória, entre outras funções psicológicas superiores. A construção de histórias a partir da realidade dos estudantes os mobiliza e engaja nos processos de aprendizado garantido maior aprendizagem. A concepção de aprendizagem mediada nas ações de ensinar indicam melhores oportunidades de aprendizagem dos estudantes com deficiência; a utilização de imagens e projetos bilíngues corroboram com o maior comprometimento do estudante surdo com o seu processo de aprendizagem; um ambiente com diversidade de objetos, imagens e cores, assim como possibilidades de locomoção e mobiliários fixos, facilitam a mobilidade do estudante autista e favorecem a realização de aprendizagens significativas.

Os resultados encontrados no estudo bibliográfico, anunciam um esforço pedagógico de garantir a aprendizagem e o desenvolvimento dos estudantes com deficiência. Apesar disso, as práticas tradicionais, na perspectiva da educação bancária, foram predominantes no levantamento realizado na revisão sistemática. Logo, tais achados ecoam como um alerta, indicando a necessidade de se realizar novas pesquisas na área, sobremodo direcionadas a explorar práticas pedagógicas na inclusão escolar que convoquem o estudante com deficiência a pensar, a saber ser e estar no mundo, mediado pelo diálogo e ações de ensinar contextualizadas e problematizadoras.

Por fim, a relevância da revisão de literatura, aqui apresentada consolida-se ao focalizar a prática pedagógica nos processos de inclusão escolar. É sabido que há uma diversidade de estudos sobre as dificuldades e desafios da inclusão, os quais são importantes para o avanço desta concepção nos sistemas educacionais no Brasil. No entanto, a prática pedagógica no contexto da inclusão dirigida ao aprender dos estudantes com deficiência requer 
mais estudos e socializações para que se evidenciem alternativas pedagógicas compatíveis com a inclusão.

\section{REFERÊNCIAS}

ANJOS, H. P. dos; MELO, L. B. de; SILVA, K. R. da; RABELO, L. C. C.; ARAÚJO, M. A. Práticas pedagógicas e inclusão: a sobrevivência da integração nos processos inclusivos. Educação \& Sociedade, 2013, v. 34, n. 123, p. 495-507. Disponível em: https://dx.doi. org/10.1590/S0101-73302013000200010. Acesso em: 30 ago. 2019.

BENITEZ, P.; DOMENICONI, C. Inclusão Escolar: o Papel dos Agentes Educacionais Brasileiros. Psicologia: Ciência e Profissão, 2015, v. 35, n. 4, p. 1007-1023. Disponível em: https://dx.doi.org/10.1590/1982-3703000652014. Acesso em: 30 ago. 2019.

BENITEZ, P.; DOMENICONI. Atuação do psicólogo na inclusão escolar de estudantes com autismo e deficiência intelectual. Psicologia Escolar e Educacional, 2018, v. 22, n. 1, p. 163-172. Disponível em: https://dx.doi.org/10.1590/2175-35392018013926. Acesso em: 30 ago. 2019.

BRASIL Constituição da República Federativa do Brasil. 1988. Brasília: DOU de 05/10/1988 (nº 191-A, Seção I, p. 1).

BRASIL. Ministério da Educação. Lei $n^{\circ}$ 9.394, de 20 de dezembro de 1996. Estabelece as diretrizes e bases da educação nacional. 1996. Disponível em: http://portal.mec.gov.br/ seesp/arquivos/pdf/lei9394_ldbn1.pdf. Acesso em: 30 ago. 2019.

BRASIL Ministério da Educação. Secretaria da Educação Especial. Política Nacional de Educação Especial, na perspectiva da Educação Inclusiva. Brasília: MEC/SEESP, 2008. Disponível em: http://portal.mec.gov.br/index.php?option=com_docman\&view=download\&alias=16690-politica-nacional-de-educacao-especial-na-perspectiva-da-educacao-inclusiva-05122014\&Itemid=30192. Acesso em: 30 ago. 2019.

BRASIL Presidência da República. Lei $n^{\circ} 13.005$, de 25 de junho de 2014. Aprova o Plano Nacional de Educação - PNE e dá outras providências. 2014. Disponível em: http://www. planalto.gov.br/ccivil_03/_ato2011-2014/2014/lei/113005.htm. Acesso em: 30 ago. 2019.

BRASIL Presidência da República. Lei $n^{\circ}$ 13.146, de 6 de julho de 2015. Lei Brasileira de Inclusão da Pessoa com Deficiência (Estatuto da Pessoa com Deficiência). 2015. Disponível em: http://www.planalto.gov.br/ccivil_03/_ato2015-2018/2015/lei/113146.htm. Acesso em: 30 ago. 2019.

BRIANT, M. E. P.; OLIVER, F. C. Inclusão de crianças com deficiência na escola regular numa região do município de São Paulo: conhecendo estratégias e ações. Revista Brasileira de Educação Especial, 2012, v. 18, n. 1, p. 141-154. Disponível em: https://dx.doi. org/10.1590/S1413-65382012000100010. Acesso em: 30 ago. 2019. 
CARAMORI, P. M.; DALL'ACQUA, M. J. C. Estratégias pedagógicas empregadas por professores de educação especial aos seus alunos com deficiência intelectual severa: um estudo descritivo da prática docente. Revista Brasileira de Educação Especial, 2015, v. 21, n. 4, p. 367-378. Disponível em: https://dx.doi.org/10.1590/S1413-65382115000400004. Acesso em: 30 ago. 2019.

COSTA, A. B.; ZOLTOWSKI, A. P. C. Como escrever um artigo de revisão sistemática In: KOLlER, S. H.; COUTO, M. C. P. de P.; HOHENDORFF, J. V. (Orgs.). Manual de produção científica. Porto Alegre: Penso, 2014. 192p. Série Métodos de Pesquisa.

FRANCO, M. A. M.; GUERRA, L. B. O ensino e a aprendizagem da criança com paralisia cerebral: ações pedagógicas possíveis no processo de alfabetização. Revista Educação Especial, 2015, v. 28, n. 52, p. 311-324. Disponível em: https://periodicos.ufsm.br/educacaoespecial/article/view/14916.Acesso em: 30 ago. 2019.

FREIRE, P. Pedagogia da autonomia: saberes necessários à prática educativa. 28. ed. São Paulo: Paz e Terra, 2003.

GIACONI, C.; RODRIGUES, M. B. Organização do espaço e do tempo na inclusão de sujeitos com autismo. Educação \& Realidade, 2014, v. 39, n. 3, p. 687-705. Disponível em: https://dx.doi.org/10.1590/S2175-62362014000300004. Acesso em: 30 ago. 2019.

GOMES, C.; SOUZA, V. L. T. de Psicologia e inclusão escolar: reflexões sobre o processo de subjetivação de professores. Psicologia: Ciência e Profissão, 2012, v. 32, n. 3, p. 588603. Disponível em: https://dx.doi.org/10.1590/S1414-98932012000300006. Acesso em: 30 ago. 2019.

GOMES, M. de F. C.; MORTIMER, E. F. Histórias sociais e singulares de inclusão: exclusão na aula de química. Cadernos de Pesquisa, 2008, v. 38, n. 133, p. 237-266. Disponível em: https://dx.doi.org/10.1590/S0100-15742008000100011. Acesso em: 30 ago. 2019.

GUEDES, M. G. de M.; LEITÃO, E. S. S. A contribuição da proposta educacional de Paulo Freire para a prática pedagógica docente na educação infantil e na educação de jovens e adultos. Revista e-Curriculum, 2016, v. 14, n.1, p. 35-55. Disponível em: https://revistas. pucsp.br/curriculum/article/view/26348. Acesso em: 14 maio 2019.

LEONARDO, N. S. T. Inclusão escolar: um estudo acerca da implantação da proposta em escolas públicas. Psicologia Escolar e Educacional, 2008, v. 12, n. 2, p. 431-440. Disponível em: https://dx.doi.org/10.1590/S1413-85572008000200014. Acesso em: 30 ago. 2019.

LOUZADA, J. C. de A.; MARTINS, S. E. S. de O. Educação inclusiva: o olhar do professor sobre a prática pedagógica para o aluno com deficiência no ensino fundamental II. Revista Ibero-Americana de Estudos em Educação, 2016, v. 11, n. 2, p. 986-999. Disponível em: https://doi.org/10.21723/riaee.v11.esp2.p986-999. Acesso em: 30 ago. 2019. 
ONU - Organização das Nações Unidas. Declaração Universal dos Direitos Humanos. 1948. Disponível em: https://nacoesunidas.org/direitoshumanos/declaracao/. Acesso em: 30 ago. 2019.

ONU - Organização das Nações Unidas. Convenção Internacional sobre os Direitos das Pessoas com Deficiência. 2006. Disponível em: http://www.un.org/disabilities/convention/ conventionfull.shtml. Acesso em: 20 maio 2019.

PLETSCH, M. D. Educação Especial e inclusão escolar: políticas, práticas curriculares e processos de ensino e aprendizagem. Poíesis Pedagógica, 2014a, v. 12, n. 1, p. 7-26. Disponível em: http://dx.doi.org/10.14507/epaa.v22n81.2014. Acesso em: 30 ago. 2019.

PLETSCH, M. D. A escolarização de pessoas com deficiência intelectual no Brasil: da institucionalização às políticas de inclusão (1973-2013). Education Policy Analysis Archives/ Archivos Analíticos de Políticas Educativas, 2014b, v. 22, n. 81. Disponível em: http:// dx.doi.org/10.14507/epaa.v22n81.2014. Acesso em: 30 ago. 2019.

SANTANA, M. L. da S.; PURIFICAÇÃO, M. M.; TEPERINO, A. P. P.; TACELI, I. C.; PESSOA, M. T. R. O brincar como elemento de inclusão de crianças caracterizadas com transtornos do espectro autista. Interfaces da Educação, 2016, v. 7, n. 19, p. 48-65. Disponível em: http://periodicosonline.uems.br/index.php/interfaces/article/view/1061/997. Acesso em: 30 ago. 2019.

SANTOS, T. C. C. dos; MARTINS, L. de A. R. Práticas de Professores Frente ao Aluno com Deficiência Intelectual em Classe Regular. Revista Brasileira de Educação Especial, 2015 , v. 21 , n. 3, p. 395-408. Disponível em: https://dx.doi.org/10.1590/S141365382115000300006. Acesso em: 30 ago. 2019.

SCHERER, R. P.; DAL'IGNA, M. C. Professoras do atendimento educacional especializado: intervenção clínica ou pedagógica? Acta Scientiarum Education, 2015, v. 37, n. 4, p. 415-425. Disponível em: http://periodicos.uem.br/ojs/index.php/ActaSciEduc/article/ view/24642/15542. Acesso em: 30 ago. 2019.

SILVA, C. L. da; LEME, M. I. da S. O papel do diretor escolar na implantação de uma cultura educacional inclusiva. Psicologia: Ciência e Profissão, 2009, v. 29, n. 3, p. 494511. Disponível em: https://dx.doi.org/10.1590/S1414-98932009000300006. Acesso em: 30 ago. 2019.

SILVA, C. M. da; SILVA, D. N. H.; SILVA, R. C. da Inclusão e processos de escolarização: narrativas de surdos sobre estratégias pedagógicas docentes. Psicologia em Estudo, Maringá, v. 19, n. 2, p. 261-271, abr.jun. 2014. Disponível em: de https://dx.doi. org/10.1590/1413-737222245009. Acesso em: 30 ago. 2019.

UNESCO - Organização das Nações Unidas para a Educação, a Ciência e a Cultura. Declaração de Salamanca e Enquadramento da Ação na Área das Necessidades Educativas 
Especiais. Lisboa: Instituto de Inovação Educacional, 1994. Disponível em: http://portal. mec.gov.br/seesp/arquivos/pdf/salamanca.pdf. Acesso em: 18 mar. 2019.

\section{DADOS DOS AUTORES}

\section{LÊda Gonçalves de Freitas}

Doutora em Psicologia pela Universidade de Brasília (UnB). Docente da Católica de Brasília (UCB), Brasília/DF - Brasil. ledagfr@gmail.com

\section{Cláudia Cristina Fukuda}

Doutora em Psicologia pela Universidade de Brasília (UnB). Docente da Católica de Brasília (UCB), Brasília/DF - Brasil. claudiafukuda@hotmail.com

\section{Carla Cristie de França Silva}

Doutora em Psicologia pela Universidade Católica de Brasília (UCB), Brasília/DF - Brasil. carlacristie@gmail.com

\section{Gustavo Francisco Neto}

Graduado em Psicologia pela Universidade Católica de Brasília (UCB), Brasília/DF - Brasil. gustawoont@gmail.com

Submetido em: $31-08-2020$

Aceito em: 31-03-2021 